\title{
Scientific Comparison Study on the Joseon Dynasty Palace Roof Tiles and Modern Handmade Roof Tiles
}

\author{
Kyoung Suk Ahn', Min Hye Lee1, Ji Hye Kim¹, Ji Hyang Ha1, Won Jin Jang', Du Hyeon Kim², Ji Youn Jeong², \\ Min Su Han ${ }^{1, *}$ \\ ${ }^{1}$ Department of Heritage Conservation and Restoration, Graduate School of Cultural Heritage, Korea National University of \\ Cultural Heritage, Buyeo 33115, Korea \\ ${ }^{2}$ Depertment of Conservation Science, Korea National University of Cultural Heritage, Buyeo 33115, Korea
}

\author{
Received: February 2, 2021 \\ Revised: February 18, 2021 \\ Accepted: February 19, 2021 \\ *Corresponding author \\ E-mail: dormer@nuch.ac.kr \\ Phone: $+82-41-830-7381$ \\ Journal of Conservation Science \\ 2021;37(1):63-76 \\ https://doi.org/10.12654/JCS.2021. \\ 37.1 .07 \\ pISSN: 1225-5459, eISSN: 2287-9781 \\ (c) The Korean Society of \\ Conservation Science for Cultural \\ Heritage \\ This is an Open-Access article distributed \\ under the terms of the Creative \\ Commons Attribution Non-Commercial \\ License (http://creativecommons.org/ \\ licenses/by-nc/3.0) which permits \\ unrestricted non-commercial use, \\ distribution, and reproduction in any \\ medium, provided the original work is \\ properly cited.
}

ABSTRACT The purpose of this study is to scientifically analyze physicochemical characteristics of the roof tiles used for palaces in the Joseon Dynasty which stored in Changdeokgung material storage and Seooreung Jaesil and the modern handmade ones which made by $\mathrm{N}$ company to understand the differences between their manufacturing techniques. Through chromaticity, cross-sectional observation, component analysis, and crystal structure analysis, it was possible to confirm the physicochemical properties and fired properties of the roof tile. Roof tiles from the Joseon Dynasty have a wider colorimetric range and higher apparent porosity and water absorption, on average, than the modern roof tiles. The cross section of the Joseon Dynasty roof tiles shows that most clay minerals have not been vitrified, remaining in the form of atypical particles, while the modern roof tiles have denser clay materials. X-ray diffraction analysis identified low-temperature minerals such as micas in Joseon roof tiles but no peak of these minerals was observed in the modern roof tiles, implying that the modern ones are fired at higher temperature than the Joseon ones. Therefore, the modern roof tiles are fired at higher temperature and have higher density than the Joseon ones due to the use of pugmills. The general content of main ingredients was similar between the two. Additionally, the principal component analysis of trace elements in the Joseon roof tiles showed that most samples were from similar areas. It seems that the Joseon roof tiles were manufactured using soils supplied from a specific region at the same timeframe and their consistency in the content of principal components implies that they also have similar mix proportions of clay.

Key Words Joseon roof tiles, Handmade roof tiles, Palace roof tiles, Firing, Mix proportion

\section{INTRODUCTION}

As part of housing culture, roof tiles are a type of construction material that represents the house owner's social status and privilege with practical functions of blocking rain and wind. The shape, pattern, and production trace of roof tiles serve as indicators of timeframe and geolocation of manufacture and technical development. Therefore, roof tiles are stereoscopic and empirical data that show us history, culture, and technology of the time and space (Kim, 2019). Although it is not known when roof tiles and roof-end tiles were first used in South Korea, it is assumed that roof tiles were introduced in the country around the time of the establishment of the Four Commanderies of Han. However, it was not until the end of the third century that their structures were adjusted to the natural and cultural conditions in Korea, resulting in Korean styles. In fact, roof-end tiles are found in the remains of the Three Kingdoms period: the Tomb of the General (Goguryeo), Hwangnyongsaji (Silla), and Mireuksaji (Baekje), with unique characteristics of each Kingdom (National Research Institute of Cultural Heritage, 2001).

Since then, roof tiles have been consistently used from Goryeo, Joseon, to modern times, and are easily found in ancient structures such as temples and palaces. Since these 
old buildings have been maintained for a long time, they can be structurally unstable if heavy roof tiles such as those used in modern architecture are connected roof tile. The Standard Specification of Properties (Cultural Heritage Administration, 2020) provides specification details and inspection methods of roof tiles used in roof construction, but Kim and Kim (2005) showed that, because modern roof tiles are mechanically manufactured, they have consistent sizes, and the compression molding process increases their density and weight. Based on that, the study suggested that further study is required to assess feasibility of mass production with techniques that can maintain the strength, water absorption, thickness, air permeability, and waterproofing performance of roof tiles.

As traditional roof tiles started to gain more attention, a study in 2009 compared properties of Joseon roof tiles and the ones made by Jewajang (masters of making roof tiles) to manufacture traditional roof tiles for restoration of the Sungnyemun Gate (National Research Institute of Cultural Heritage, 2009). In 2012, as part of establishing a promotion plan of traditional roof tiles and bricks, a study was conducted to understand physicochemical characteristics of traditional roof tiles from Baekje, Unified Silla, Joseon, and modern days (Cultural Heritage Administration, 2012).

Previous studies were mainly focused on traditional roof tiles and those that are being produced in the modern era, but it was hard to obtain specific results on the physical properties of the Joseon Dynasty roof tiles, because there was no diversity in the shapes of the roof tiles used in the study along with a small sample of roof tile. To this end, handmade traditional roof tiles fired in a traditional kiln, one of the three types of roof tiles specified in the Standard Specification of Properties (Cultural Heritage Administration, 2020), were used as a control group and compared with the roof tiles used in the Joseon Dynasty palaces.

This study aims to conduct scientific analysis on the roof tiles used in palaces of the Joseon Dynasty and traditional roof tiles manufactured in modern days, which allows us to compare basic properties by manufacture timeframe and specification. Results are expected to contribute to future studies on manufacture technology and properties of traditional roof tiles. Also providing scientific data, it can be used for research on roof tile restoration of the Joseon Dynasty.

\section{MATERIAL AND METHOD}

\subsection{Subjects of study}

The subjects are 54 samples of Joseon roof tiles and 34 modern roof tiles. As for Joseon roof tiles, eight samples were selected for each of the shapes and specifications from intact roof tiles kept in the supportive material storage of the Changdeokgung and the Jaesil of the Seooreung Royal Tomb. For some of the samples, only two were available due to limited quantity in storage. The roof tiles that were in the possession of the Changdeokgung material storage and the Seooreung Jaesil are all roof tiles used in Changdeokgung during the Joseon Dynasty.

Table 1. List of roof tile samples in this study

\begin{tabular}{ccc}
\hline Source & Type & Sample name \\
\hline \multirow{3}{*}{$\begin{array}{c}\text { Changdeokgung } \\
\text { material storage }\end{array}$} & Large concave eave-end roof tile & DAM1 DAM8 \\
\cline { 2 - 3 } & Small channel roof tile & SAK1 $\sim$ SAK8 \\
\cline { 2 - 3 } & Small concave eave-end roof tile & SAM1 SAM8 \\
\cline { 2 - 3 } Seooreung Jaesil & Small convex roof tile & SSK1 $\sim$ SSK8 \\
\cline { 2 - 3 } & Large channel roof tile & DAK1 $\sim$ DAK8 \\
\cline { 2 - 3 } & Large convex-end roof tile & DSM1 DSM6 \\
\hline \multirow{3}{*}{ 'N' company } & Small convex-end roof tile & SSM1 $\sim$ SSM2 \\
\cline { 2 - 3 } & Tiny convex roof tile & NAK1 $\sim$ NAK8 \\
\cline { 2 - 3 } & Channel roof tile & NAM1 $\sim$ NAM9 \\
\hline
\end{tabular}




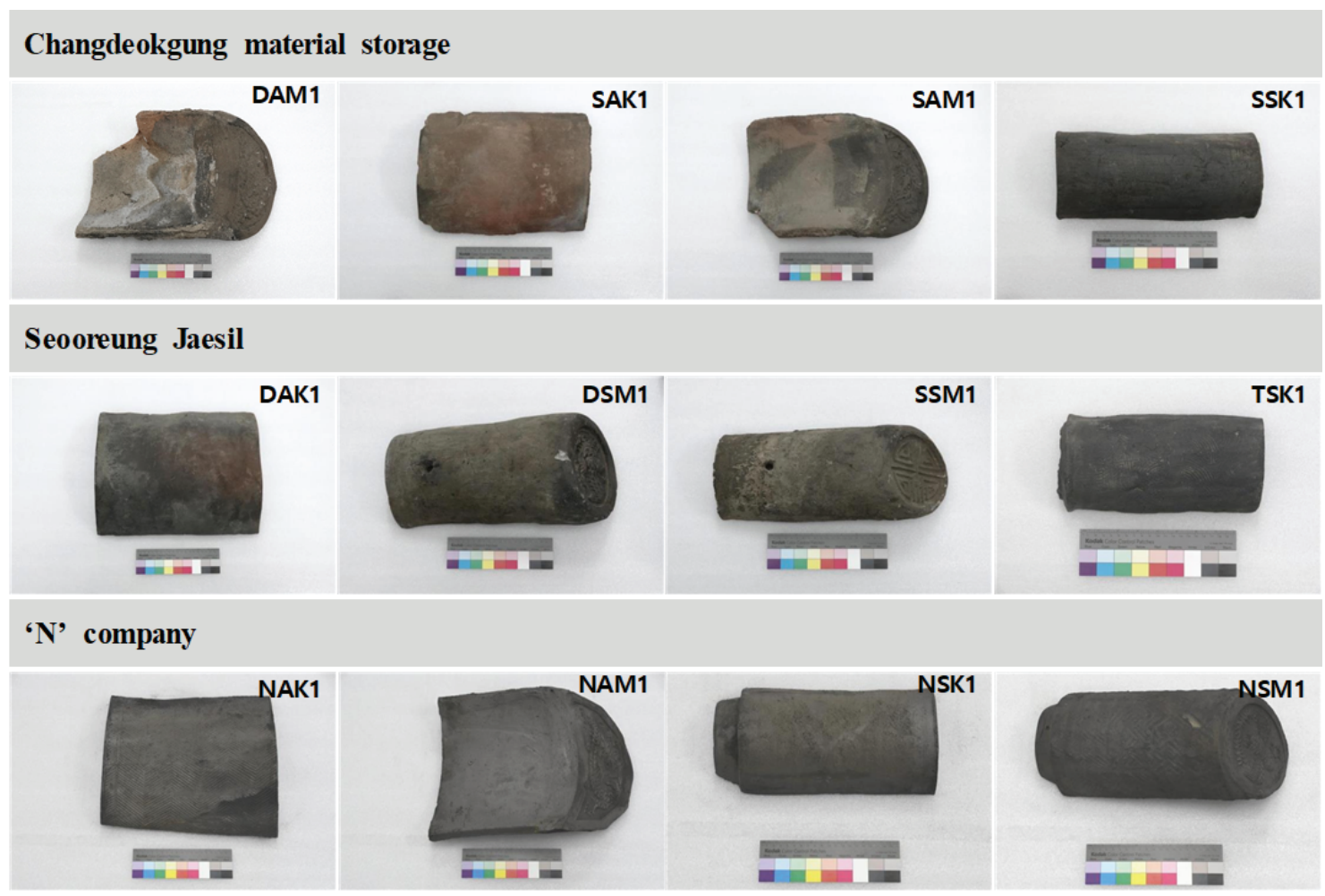

Figure 1. Roof tile samples in this study.

As for modern roof tiles, the samples were purchased from $\mathrm{N}$ company, a manufacturer that fired handmade traditional roof tiles in a traditional kiln. Like Joseon roof tile samples, 8 or more samples were selected for each of the shapes and specifications, which amount to 34 samples (Table 1, Figure 1).

\subsection{Method}

Color of roof tiles varies depending on the ingredients of the clay, baking conditions and surroundings, and baking time. To verify the factors, chromaticity was measured using a chromameter (CR-400, Minolta, JPN). Using D60, three pictures were taken at a time. The front and back sides were separately measured, and the parts that looked different in color to the naked eye were measured three times and averaged. Voids on the surface and inside of the roof tiles reflect the information of characteristics of the raw materials and baking conditions. To compare physical traits based on the voids, apparent and bulk specific gravities, water absorption, and apparent porosity were measured and compared. A precision electronic scale (GR-200, A\&D, JPN) and a hydrometry kit (AD-1653, A\&D, JPN) were used for the measurement. To measure physical characteristics of the clay material, the surfaces were polished to remove any textures and contaminations and completely dried at $100 \pm$ $5^{\circ} \mathrm{C}$ for over $24 \mathrm{~h}$. The weight in the dried status was calculated, and then the roof tiles were immersed in distilled water for over $24 \mathrm{~h}$ to measure its weight and the weight in the water. Apparent and bulk specific gravities, water absorption, and apparent porosity were calculated with the following KS L 4008.

To observe cross sections, the samples were cut and fixed on epoxy resin. Then, the cross sections were polished using a grinder (Rotopol-11, Struers, DNK) and sandpapers \#220, $\# 500$, \#1200, \#2400, and \#4000 in the order. Their layer formations were examined using a stereoscopic microscope (SMZ800N, Nickon, JPN). After they were examined with the stereoscopic microscope, their surfaces were coated with gold and examined for the clay materials through secondary electron images from a scanning electron microscope (FlexSEM 1000, Horiba, JPN). 
The Seoul Center of the Korea Basic Science Institute (KBSI) analyzed the clay materials using an X-ray fluorescence spectrometer (PHILIPS PW 2404, Philips, NLD). Contaminated surfaces of the samples were washed off with distilled water, and parts of the samples were collected and dried at $105^{\circ} \mathrm{C}$ for over $24 \mathrm{~h}$. Samples were dried, powdered with a mortar, completely dried in glass vials at $105^{\circ} \mathrm{C}$ for over $24 \mathrm{~h}$, and examined using X-ray fluorescence spectrometer for their main elements. KBSI analyzed trace elements of the clay materials using an inductively coupled plasma (ICP) system. Some samples were collected from the inside that was not contaminated and powdered. KBSI conducted principal component analysis (PCA) with an ICP-atomic emission spectrometer (ICP-AES) and trace elements and rare earth elements analysis with an ICP-mass spectrometer (ICP-MS), after pretreating the samples using the acid hydrolysis method. To identify minerals in the samples, their crystal structures were analyzed using X-ray diffractometer (Miniflex600, Rigaku, JPN). Parts of the samples were collected, powdered with a mortar, and dried in glass vials at $105^{\circ} \mathrm{C}$ for over $24 \mathrm{~h}$. Powder samples were analyzed in sample holders. The analysis was performed at $40 \mathrm{kV}, 15 \mathrm{~mA}, 5^{\circ}-80^{\circ}$, and $2^{\circ} / 1 \mathrm{~min}$ on a spinner stage.

\section{ANALYSIS RESULTS}

\subsection{Physical characteristics}

\subsubsection{Chromaticity}

Chromaticity is a physical property that is very useful to investigate firing conditions, including firing temperature, firing time, and firing atmosphere of an oxidation-reduction reaction, and to understand characteristics of materials. The chromaticity of the back surfaces of the roof tiles was measured and illustrated in the CIE LAB color space.

The chromaticity analysis shows the overall lightness $\left(\mathrm{L}^{*}\right)$ of $25 \sim 55$, with $a^{*}$ values of $-2 \sim 6$ and $b^{*}$ values of $0 \sim 15$ (Figure 2). Joseon roof tiles have a wider range of chromaticity than modern roof tiles, which have concentrated chromaticity values. This may be because it was more difficult to adjust the temperature gradient in kilns in the Joseon Dynasty than modern ones, and different factors, such as arrangement and shapes of roof tiles, may have caused differences in colors. However, the Joseon roof tiles used in the analysis were used ones with contamination traces of calcification or soils and exposed to external environments for a significant period of time, so it should be considered that the color might have changed from the time of manufacture. Modern roof tiles were fired in the same kiln, hardly giving any differences in colors. However, they have a wide range of chromaticity, which may be attributed to the metallic phototropic properties visible even to the naked eyes, showing themselves on the sample surfaces with different lightness values.

\subsubsection{Specific gravity}

Bulk specific gravity, apparent porosity, and water absorption of Joseon and modern roof tiles were measured (Figures $3 \sim 5$ ). The average bulk specific gravity of Joseon roof tiles is 1.74 , which is a bit lower than but similar to the average of modern roof tiles, which is 1.97 . The average apparent porosity of Joseon roof tiles is 43.65 and the water
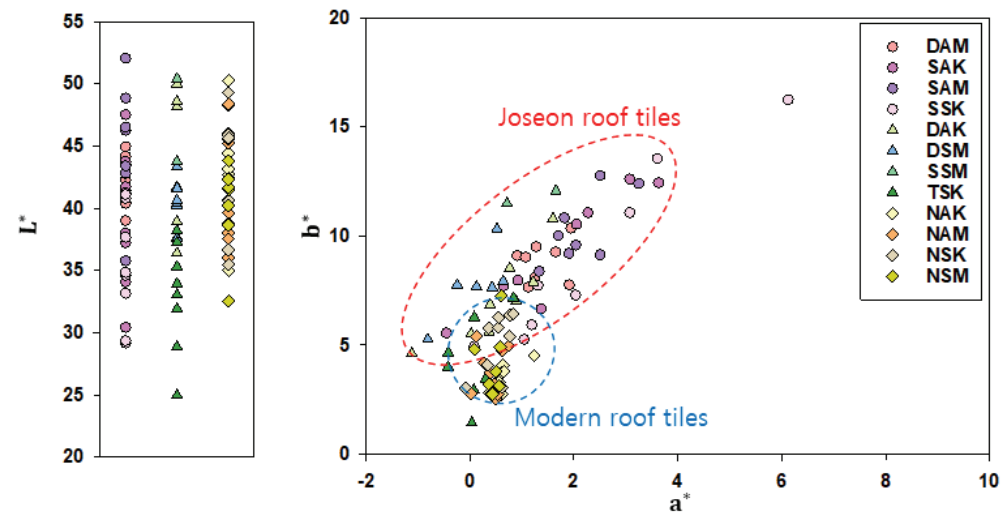

Figure 2. Color coordinates of roof tiles. 

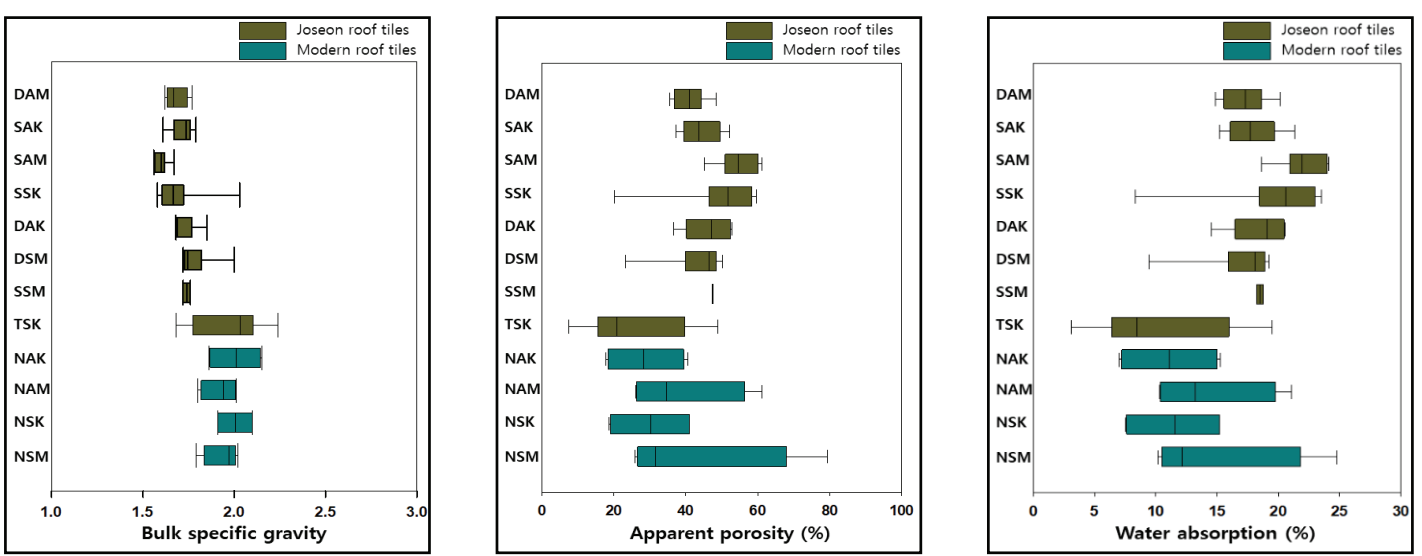

Figure 3. Graph of bulk specific gravity. Figure 4. Graph of apparent porosity. Figure 5. Graph of water absorption.

absorption is 17.56 , which are higher than 35.01 and 12.96 , respectively, of modern roof tiles. The Standard Specification of Properties requires the water absorption of Korean traditional roof tiles to be $16 \%$ or lower (Cultural Heritage Administration, 2020). Among the roof tiles analyzed, the water absorption of the modern roof tiles is $16 \%$ or lower on average, while most of the Joseon roof tiles show a water absorption of $16 \%$ or higher. However, it should be noted that the properties of Joseon roof tiles have changed compared to the time of manufacture due to exposure to external climates for a significant period of time. As roof tiles deteriorate, the density and bulk specific gravity decreases, and more air bubbles increase porosity and water absorption. Therefore, the Joseon and modern roof tiles cannot be directly compared via specific gravity and water absorption, because the former deteriorated and the latter has been recently manufactured. Compared to modern roof tiles, the Joseon roof tiles have a higher water absorption, and tiny convex roof tiles have an apparent porosity and water absorption similar to those of modern handmade roof tiles, even though they are old roof tiles. Also, only the inner parts were measured after the outer surfaces were removed, and thus, the value is assumed to be similar to the actual initial water absorption.

\subsection{Cross-sectional observation}

Cross-sectional observation shows that the roof tiles from the storage of the Changdeokgung can be classified into red-yellow, gray-blue, and gray families, each with different characteristics (Figure 6). Seooreung roof tiles have a variety of clay colors such as gray, yellow, purple, and green-gray, and lower lightness in general than Changdeokgung ones, giving darker colors. Most of the time, large roof-end tiles show gray and yellow clay materials, DAK uneven gray and some yellow, DSM and SSM somewhat similar gray, and TSK darker black-gray clay materials.

Modern roof tiles commonly display red mineral particles in parts. First, they are denser than Joseon ones, with NAK and NAM containing highly bluish gray clay, and NSK and NSM containing highly yellowish or reddish gray clay. Overall, the modern roof tiles feature several black particles, which have high roundness. Their air bubbles tend to be long and arranged side by side.

Joseon roof tiles showed a wide range of clay colors including brown, gray-blue, gray, and red-yellow, while modern roof tiles feature gray clay materials. The difference in clay colors is attributed to the ability to consistently adjust firing temperature and conditions due to the improvement of manufacturing techniques.

Scanning electron microscope revealed that Joseon roof tiles have atypical particles of most clay minerals that have not been vitrified. Clay material particles were mostly fine grained to cryptocrystalline. Some of the mineral particles like quartz are medium-sized, but most have similar sizes, demonstrating well-selected clay materials. However, cross sections of convex roof tiles like SSK1 and TSK1 show vitrification in process, and the color is black-gray, unlike other Joseon roof tiles. It may be because of the differences in firing conditions such as shape and arrangement.

As a result of observation with the scanning electron 


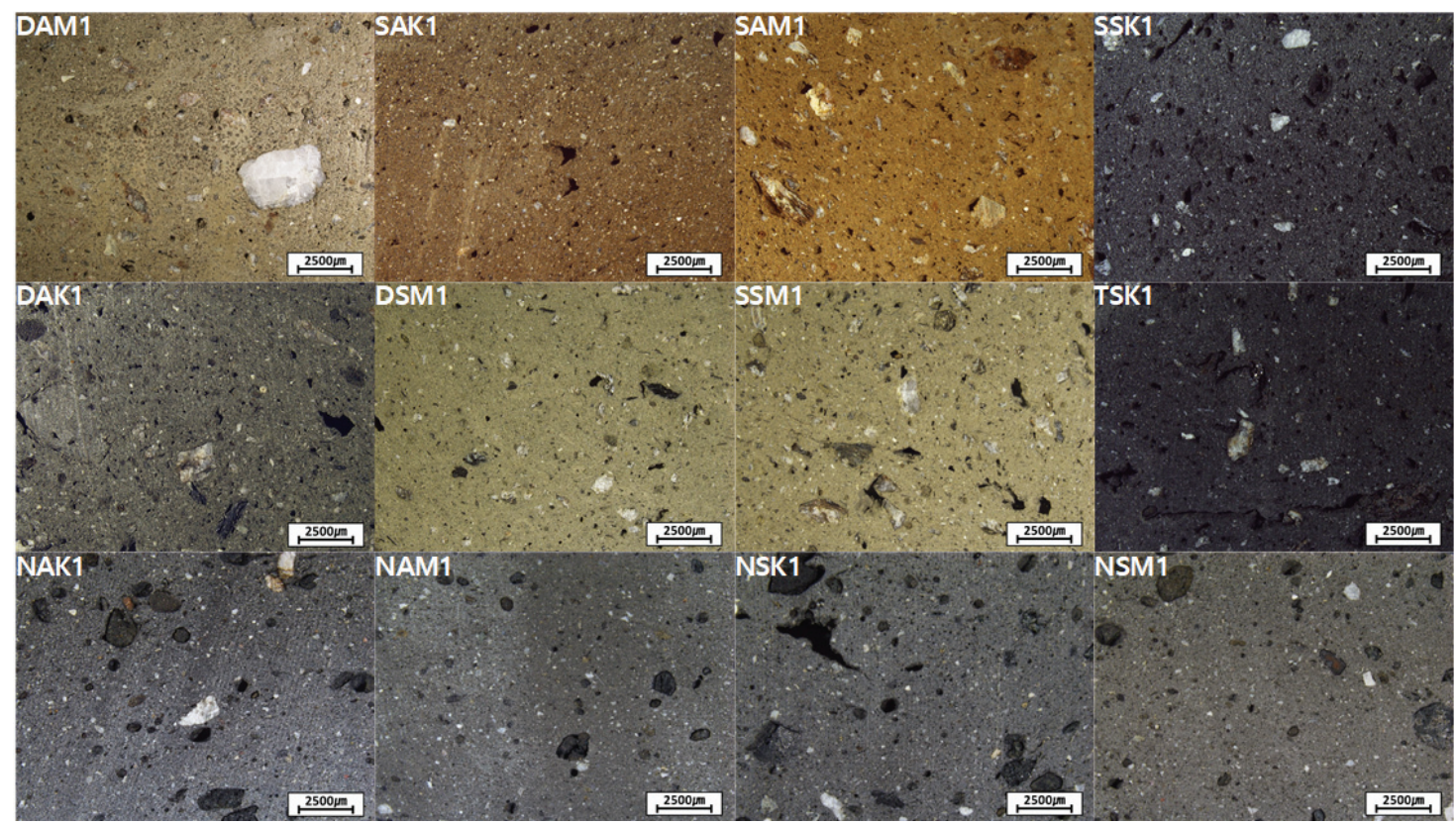

Figure 6. Microstructure images of Joseon roof tiles and Modern roof tiles observed by optical microscope.

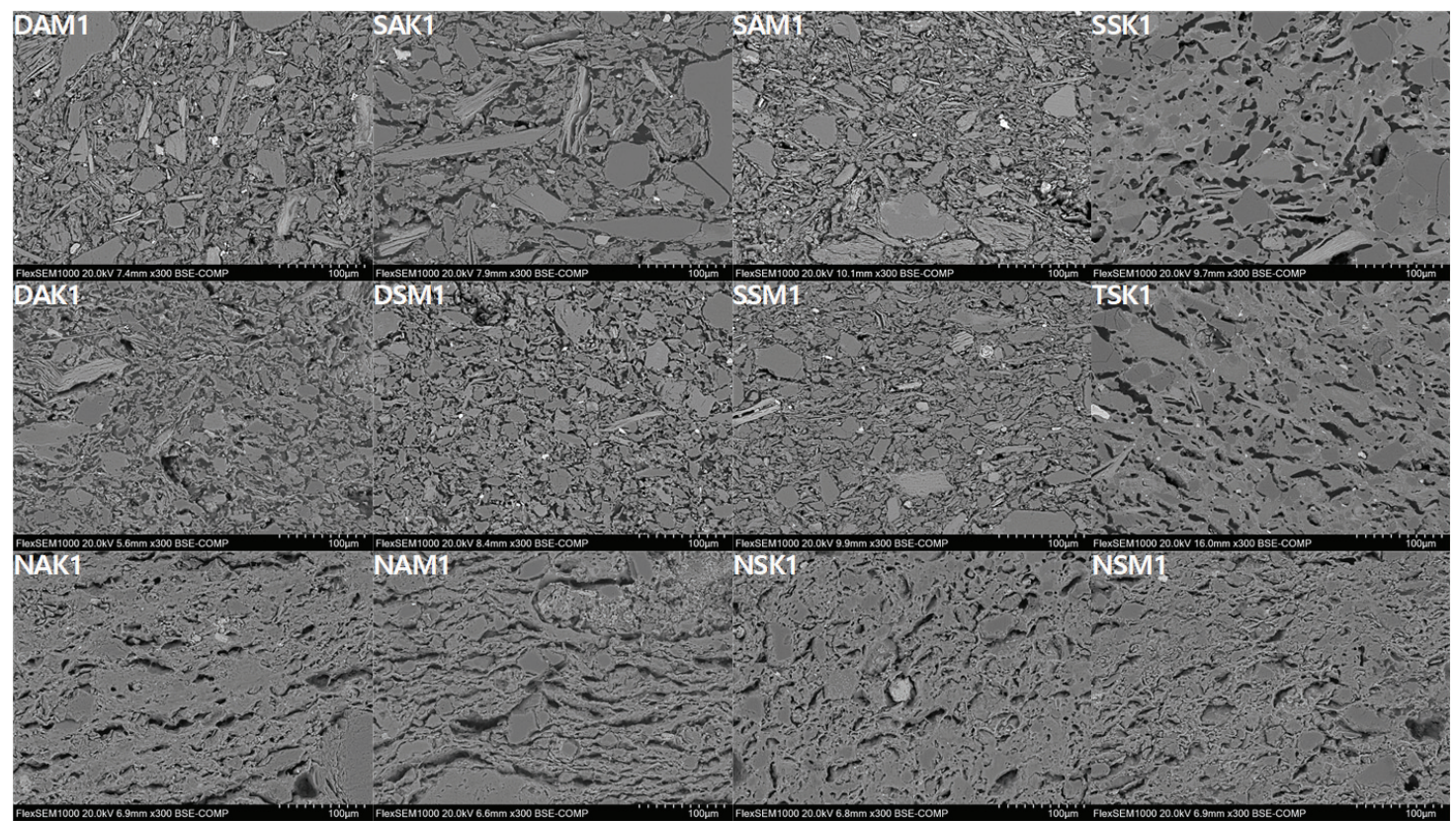

Figure 7. Microstructure images of Joseon roof tiles and Modern roof tiles observed by scanning electron microscope.

microscope of the modern tile, it was possible to observe the vitrified cross section in all samples, which could be confirmed that it was fired at a higher temperature than that of the Joseon Dynasty roof tiles and it can be seen that it was fired evenly regardless of the type or shape of the roof tiles.

\subsection{Chemical characteristics}

\subsubsection{Principal elements}

Joseon and modern roof tiles show principal elements of $67 \sim 68 \mathrm{wt} \%$ of $\mathrm{SiO}_{2}, 17 \sim 18 \mathrm{wt} \%$ of $\mathrm{Al}_{2} \mathrm{O}_{3}$, and $6 \mathrm{wt} \%$ of $\mathrm{Fe}_{2} \mathrm{O}_{3}$, with similar proportions (Table 2). 
Table 2. Principal elements concentration of roof tiles

\begin{tabular}{|c|c|c|c|c|c|c|c|c|c|c|c|c|}
\hline \multirow{2}{*}{$\begin{array}{l}\text { Sample } \\
\text { number }\end{array}$} & \multicolumn{12}{|c|}{ Oxide concentration (wt\%) } \\
\hline & $\mathrm{SiO}_{2}$ & $\mathrm{Al}_{2} \mathrm{O}_{3}$ & $\mathrm{Fe}_{2} \mathrm{O}_{3}{ }^{*}$ & $\mathrm{CaO}$ & $\mathrm{K}_{2} \mathrm{O}$ & MgO & $\mathrm{Na}_{2} \mathrm{O}$ & $\mathrm{TiO}_{2}$ & $\mathrm{P}_{2} \mathrm{O}_{5}$ & $\mathrm{MnO}$ & L.O.I & Total \\
\hline DAM1 & 69.2 & 16.0 & 5.29 & 1.29 & 2.84 & 1.45 & 0.716 & 0.786 & 0.148 & 0.097 & 1.89 & 99.8 \\
\hline DAM2 & 65.1 & 18.8 & 6.79 & 0.644 & 2.82 & 1.85 & 0.592 & 0.872 & 0.169 & 0.103 & 0.422 & 98.1 \\
\hline DAM3 & 64.0 & 19.3 & 6.83 & 0.784 & 2.95 & 1.86 & 0.573 & 0.885 & 0.164 & 0.104 & 0.823 & 98.3 \\
\hline DAM4 & 67.3 & 16.5 & 5.53 & 1.64 & 2.85 & 1.44 & 0.480 & 0.783 & 0.099 & 0.076 & 2.07 & 98.8 \\
\hline DAM5 & 64.3 & 19.6 & 7.08 & 0.846 & 2.95 & 1.93 & 0.632 & 0.900 & 0.198 & 0.101 & 0.660 & 99.2 \\
\hline DAM6 & 64.6 & 18.6 & 6.69 & 0.968 & 2.81 & 1.81 & 0.607 & 0.868 & 0.169 & 0.086 & 0.852 & 98.0 \\
\hline DAM7 & 69.6 & 16.3 & 5.54 & 0.551 & 2.85 & 1.55 & 0.581 & 0.794 & 0.123 & 0.094 & 0.242 & 98.3 \\
\hline DAM8 & 70.0 & 16.2 & 5.61 & 0.683 & 2.86 & 1.58 & 0.737 & 0.802 & 0.131 & 0.090 & 0.412 & 99.0 \\
\hline SAK1 & 66.9 & 16.8 & 5.82 & 0.913 & 3.16 & 1.73 & 1.29 & 0.795 & 0.166 & 0.089 & 0.580 & 98.3 \\
\hline SAK2 & 65.7 & 18.2 & 6.26 & 0.916 & 3.06 & 1.72 & 0.884 & 0.905 & 0.228 & 0.090 & 0.488 & 98.4 \\
\hline SAK3 & 66.4 & 18.5 & 6.99 & 0.270 & 2.80 & 1.38 & 0.140 & 0.946 & 0.146 & 0.079 & 0.600 & 98.2 \\
\hline SAK4 & 69.1 & 16.5 & 5.65 & 0.455 & 3.00 & 1.54 & 0.707 & 0.786 & 0.119 & 0.087 & 0.224 & 98.2 \\
\hline SAK5 & 64.9 & 20.1 & 6.13 & 0.649 & 2.84 & 1.42 & 0.664 & 0.908 & 0.158 & 0.053 & 0.604 & 98.4 \\
\hline SAK6 & 68.2 & 16.9 & 5.97 & 0.642 & 2.76 & 1.57 & 0.685 & 0.837 & 0.163 & 0.081 & 0.547 & 98.3 \\
\hline SAK7 & 67.8 & 17.3 & 6.42 & 0.472 & 2.85 & 1.50 & 0.537 & 0.901 & 0.102 & 0.108 & 0.632 & 98.6 \\
\hline SAK8 & 66.0 & 18.7 & 6.47 & 0.489 & 2.86 & 1.36 & 0.500 & 0.893 & 0.097 & 0.061 & 0.637 & 98.1 \\
\hline SAM1 & 64.7 & 18.9 & 7.06 & 0.462 & 2.78 & 1.96 & 0.438 & 0.902 & 0.137 & 0.090 & 0.554 & 98.0 \\
\hline SAM2 & 63.6 & 19.6 & 7.10 & 0.588 & 2.89 & 1.92 & 0.536 & 0.917 & 0.180 & 0.093 & 0.599 & 98.0 \\
\hline SAMB & 63.1 & 20.1 & 7.18 & 0.529 & 2.86 & 1.91 & 0.486 & 0.931 & 0.169 & 0.110 & 0.889 & 98.2 \\
\hline SAM4 & 64.1 & 19.2 & 7.22 & 0.445 & 2.80 & 1.95 & 0.521 & 0.919 & 0.147 & 0.096 & 0.806 & 98.2 \\
\hline SAM5 & 66.0 & 18.0 & 6.54 & 0.702 & 2.88 & 1.92 & 0.669 & 0.896 & 0.177 & 0.106 & 0.626 & 98.5 \\
\hline SAM6 & 64.2 & 18.8 & 6.90 & 0.755 & 2.80 & 1.90 & 0.714 & 0.919 & 0.221 & 0.099 & 1.052 & 98.3 \\
\hline SAM7 & 64.9 & 18.6 & 6.63 & 0.643 & 2.96 & 1.88 & 0.743 & 0.885 & 0.163 & 0.090 & 0.702 & 98.2 \\
\hline SAM8 & 66.5 & 18.0 & 5.38 & 0.823 & 3.02 & 1.71 & 1.05 & 0.849 & 0.162 & 0.075 & 0.764 & 98.3 \\
\hline SSK1 & 67.0 & 17.6 & 6.25 & 0.757 & 2.96 & 1.85 & 1.00 & 0.846 & 0.134 & 0.094 & 0.098 & 98.6 \\
\hline SSK2 & 66.2 & 18.2 & 6.39 & 0.627 & 2.94 & 1.86 & 0.737 & 0.880 & 0.156 & 0.096 & 0.129 & 98.2 \\
\hline SSK3 & 67.4 & 17.5 & 6.02 & 0.742 & 2.90 & 1.68 & 0.802 & 0.886 & 0.127 & 0.090 & 0.254 & 98.3 \\
\hline SSK4 & 66.2 & 18.0 & 6.31 & 0.695 & 2.96 & 1.89 & 0.936 & 0.869 & 0.149 & 0.109 & 0.528 & 98.7 \\
\hline SSK5 & 66.3 & 17.6 & 6.27 & 0.691 & 2.96 & 1.83 & 0.913 & 0.877 & 0.162 & 0.107 & 0.398 & 98.1 \\
\hline SSK6 & 66.9 & 17.6 & 5.86 & 0.760 & 2.82 & 1.65 & 0.711 & 0.871 & 0.125 & 0.085 & 0.671 & 98.0 \\
\hline SSK7 & 65.9 & 18.1 & 6.35 & 0.700 & 2.94 & 1.86 & 0.801 & 0.878 & 0.185 & 0.094 & 0.441 & 98.2 \\
\hline SSK8 & 67.2 & 17.5 & 5.92 & 0.556 & 2.88 & 1.65 & 0.828 & 0.878 & 0.136 & 0.089 & 0.587 & 98.1 \\
\hline DAK1 & 70.4 & 16.0 & 5.87 & 0.440 & 2.46 & 1.63 & 0.522 & 0.907 & 0.089 & 0.092 & 0.090 & 98.5 \\
\hline DAK2 & 68.6 & 17.9 & 6.71 & 0.196 & 2.32 & 1.32 & 0.134 & 0.897 & 0.080 & 0.081 & 0.049 & 98.3 \\
\hline DAK3 & 64.0 & 19.5 & 6.88 & 0.749 & 2.97 & 1.89 & 0.717 & 0.900 & 0.161 & 0.108 & 0.176 & 98.0 \\
\hline DAK4 & 68.1 & 16.5 & 5.81 & 0.639 & 2.84 & 1.60 & 0.745 & 0.961 & 0.101 & 0.099 & 0.658 & 98.0 \\
\hline DAK5 & 69.7 & 16.0 & 5.57 & 0.636 & 2.88 & 1.56 & 1.05 & 0.828 & 0.112 & 0.091 & 0.096 & 98.5 \\
\hline DAK6 & 68.5 & 16.3 & 6.10 & 0.565 & 2.81 & 1.58 & 0.731 & 0.869 & 0.124 & 0.135 & 0.256 & 98.0 \\
\hline
\end{tabular}




\begin{tabular}{|c|c|c|c|c|c|c|c|c|c|c|c|c|}
\hline \multirow{2}{*}{$\begin{array}{l}\text { Sample } \\
\text { number }\end{array}$} & \multicolumn{12}{|c|}{ Oxide concentration (wt\%) } \\
\hline & $\mathrm{SiO}_{2}$ & $\mathrm{Al}_{2} \mathrm{O}_{3}$ & $\mathrm{Fe}_{2} \mathrm{O}_{3}{ }^{*}$ & $\mathrm{CaO}$ & $\mathrm{K}_{2} \mathrm{O}$ & MgO & $\mathrm{Na}_{2} \mathrm{O}$ & $\mathrm{TiO}_{2}$ & $\mathbf{P}_{2} \mathbf{O}_{5}$ & $\mathrm{MnO}$ & L.O.I & Total \\
\hline DAK7 & 69.6 & 16.5 & 5.34 & 0.534 & 2.81 & 1.60 & 0.541 & 0.848 & 0.105 & 0.085 & 0.419 & 98.3 \\
\hline DAK8 & 63.8 & 19.9 & 6.72 & 0.598 & 2.98 & 1.83 & 0.980 & 0.910 & 0.143 & 0.098 & 0.281 & 98.2 \\
\hline DSM1 & 68.1 & 17.2 & 5.98 & 0.572 & 2.65 & 1.54 & 0.686 & 0.863 & 0.164 & 0.075 & 0.211 & 98.0 \\
\hline DSM2 & 68.6 & 16.8 & 5.31 & 0.628 & 2.88 & 1.58 & 0.542 & 0.857 & 0.103 & 0.080 & 0.632 & 98.0 \\
\hline DSM3 & 69.7 & 15.8 & 5.83 & 0.437 & 2.44 & 1.78 & 0.667 & 0.932 & 0.074 & 0.107 & 0.254 & 98.1 \\
\hline DSM4 & 67.8 & 17.2 & 6.27 & 0.585 & 2.74 & 1.73 & 0.851 & 0.888 & 0.091 & 0.104 & 0.021 & 98.3 \\
\hline DSM5 & 68.2 & 17.1 & 6.17 & 0.527 & 2.68 & 1.72 & 0.687 & 0.893 & 0.105 & 0.097 & 0.102 & 98.3 \\
\hline DSM6 & 69.8 & 15.7 & 5.79 & 0.414 & 2.48 & 1.73 & 0.562 & 0.917 & 0.281 & 0.097 & 0.188 & 98.0 \\
\hline SSM1 & 69.7 & 16.2 & 5.81 & 0.369 & 2.58 & 1.81 & 0.525 & 0.923 & 0.073 & 0.102 & 0.133 & 98.3 \\
\hline SSM2 & 68.1 & 17.2 & 6.16 & 0.525 & 2.70 & 1.72 & 0.650 & 0.888 & 0.110 & 0.097 & 0.152 & 98.2 \\
\hline TSK1 & 66.3 & 18.6 & 6.76 & 0.486 & 2.93 & 1.56 & 0.401 & 0.875 & 0.104 & 0.091 & 0.306 & 98.4 \\
\hline TSK2 & 67.9 & 17.2 & 6.19 & 0.508 & 2.84 & 1.56 & 0.457 & 0.890 & 0.084 & 0.102 & 0.286 & 98.0 \\
\hline TSK3 & 66.7 & 17.6 & 6.37 & 0.684 & 2.93 & 1.70 & 0.795 & 0.904 & 0.101 & 0.107 & 0.402 & 98.3 \\
\hline TSK4 & 67.4 & 18.2 & 6.42 & 0.391 & 2.82 & 1.15 & 0.274 & 0.868 & 0.088 & 0.068 & 0.283 & 98.0 \\
\hline TSK5 & 66.6 & 18.3 & 6.54 & 0.449 & 2.84 & 1.59 & 0.432 & 0.937 & 0.118 & 0.086 & 0.196 & 98.1 \\
\hline TSK6 & 64.1 & 20.4 & 7.32 & 0.430 & 2.95 & 1.39 & 0.466 & 0.857 & 0.127 & 0.061 & 0.102 & 98.3 \\
\hline TSK7 & 64.6 & 20.0 & 6.91 & 0.464 & 2.81 & 1.29 & 0.481 & 0.862 & 0.126 & 0.058 & 0.422 & 98.1 \\
\hline TSK8 & 66.4 & 16.2 & 5.12 & 0.718 & 2.68 & 1.23 & 0.935 & 0.788 & 0.111 & 0.043 & 3.774 & 98.0 \\
\hline NAK1 & 70.9 & 15.6 & 6.86 & 0.410 & 1.63 & 0.85 & 0.566 & 0.925 & 0.049 & 0.106 & 0.268 & 98.1 \\
\hline NAK2 & 71.6 & 15.3 & 6.58 & 0.436 & 1.68 & 0.87 & 0.614 & 0.924 & 0.050 & 0.120 & 0.271 & 98.5 \\
\hline NAK3 & 69.1 & 17.2 & 5.90 & 0.466 & 2.15 & 1.03 & 0.817 & 0.906 & 0.042 & 0.086 & 0.235 & 98.0 \\
\hline NAK4 & 69.4 & 17.5 & 5.26 & 0.910 & 1.98 & 0.94 & 0.890 & 0.816 & 0.036 & 0.077 & 0.295 & 98.1 \\
\hline NAM1 & 71.1 & 15.5 & 6.60 & 0.429 & 1.65 & 0.84 & 0.576 & 0.936 & 0.049 & 0.126 & 0.267 & 98.1 \\
\hline NAM2 & 69.7 & 17.0 & 5.94 & 0.491 & 2.12 & 1.00 & 0.807 & 0.901 & 0.042 & 0.089 & 0.029 & 98.1 \\
\hline NAM3 & 71.1 & 15.5 & 6.68 & 0.427 & 1.65 & 0.84 & 0.565 & 0.923 & 0.049 & 0.107 & 0.326 & 98.2 \\
\hline NAM4 & 69.5 & 16.7 & 5.71 & 0.546 & 2.11 & 0.96 & 1.49 & 0.882 & 0.040 & 0.093 & 0.069 & 98.0 \\
\hline NSK1 & 71.0 & 15.4 & 6.88 & 0.421 & 1.63 & 0.84 & 0.589 & 0.923 & 0.052 & 0.124 & 0.309 & 98.2 \\
\hline NSK2 & 69.9 & 16.5 & 5.88 & 0.532 & 2.10 & 0.96 & 0.841 & 0.882 & 0.040 & 0.091 & 0.295 & 98.0 \\
\hline NSK3 & 70.9 & 15.5 & 6.95 & 0.418 & 1.65 & 0.86 & 0.593 & 0.930 & 0.052 & 0.112 & 0.327 & 98.3 \\
\hline NSK4 & 69.5 & 16.9 & 5.82 & 0.495 & 2.15 & 1.00 & 1.56 & 0.894 & 0.042 & 0.100 & 0.284 & 98.8 \\
\hline NSM1 & 71.2 & 15.3 & 6.74 & 0.483 & 1.67 & 0.86 & 0.590 & 0.940 & 0.051 & 0.108 & 0.255 & 98.2 \\
\hline NSM2 & 71.4 & 15.2 & 6.56 & 0.436 & 1.66 & 0.84 & 0.638 & 0.925 & 0.049 & 0.104 & 0.270 & 98.0 \\
\hline NSM3 & 71.3 & 15.2 & 6.55 & 0.436 & 1.65 & 0.84 & 0.937 & 0.915 & 0.049 & 0.103 & 0.261 & 98.2 \\
\hline NSM4 & 69.8 & 17.0 & 5.95 & 0.471 & 2.16 & 1.02 & 0.808 & 0.904 & 0.046 & 0.090 & 0.228 & 98.5 \\
\hline
\end{tabular}

To verify characteristics of roof tile ingredients, the contents of principal elements conversed using the Serger formula, and against the total neutral oxide $\left(\mathrm{R}_{2} \mathrm{O}_{3}\right)$ as 1 , the relative molar ratio of the acid oxide $\left(\mathrm{RO}_{2}\right)$, which is a glass former, and that of alkaline oxide $\left(\mathrm{RO}+\mathrm{R}_{2} \mathrm{O}\right)$, which serves as flux, were compared (Figure 8). Properties of roof tiles change after baking according to the proportion of each oxide in the Serger formula; typically, the lower the $\mathrm{RO}_{2}$ value, the higher the fire resistance and plasticity; when the $\mathrm{RO}+\mathrm{R}_{2} \mathrm{O}$ value is high, it can melt even at relatively low temperature 


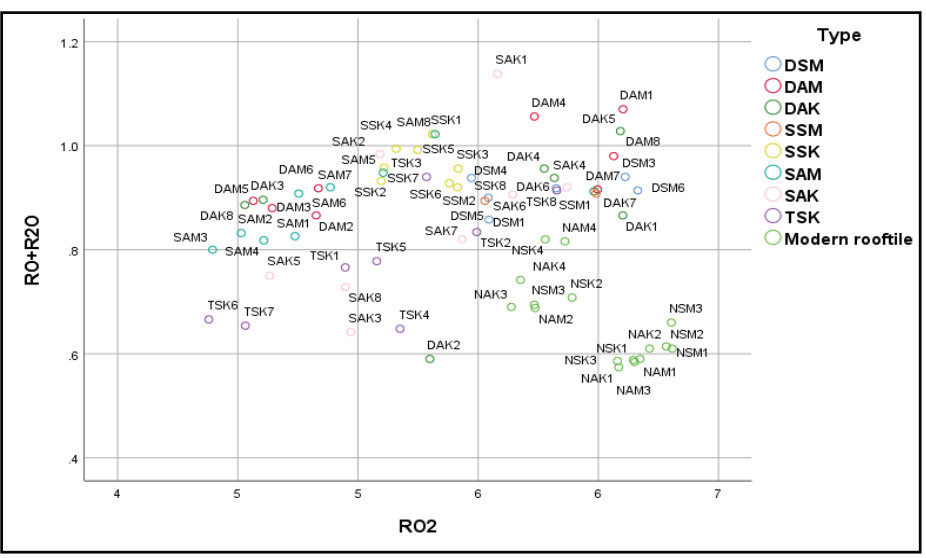

Figure 8. Seger formula graph of principal elements.

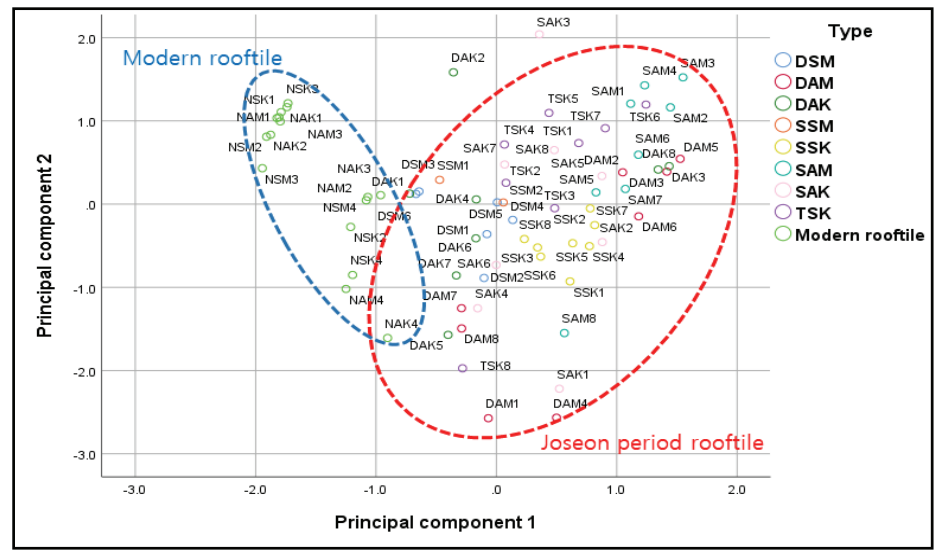

Figure 9. PCA results of principal elements.

(Han, 2006). Joseon roof tiles possessed their most $\mathrm{RO}_{2}$ value in the range of $4.5 \sim 6.5$, and the modern roof tiles from $\mathrm{N}$ company showed relatively high $\mathrm{RO}_{2}$ values. Moreover, the $\mathrm{RO}+\mathrm{R}_{2} \mathrm{O}$ values of most Joseon roof tiles fall under the range of $0.6 \sim 1.2$, while modern roof tiles have values of $\sim 0.6$.

To compare the relationship between principal elements of Joseon and modern roof tiles, a principal component analysis (PCA) was conducted with eight compositions of major oxides as variables (Figure 9). A PCA refers to an analysis method of compressing data with countless variables into principal components considering the relationship between the variables o minimize loss of multidimensional data and display the data in a low-dimensional space (Son, 2018). The analysis showed that Joseon roof tiles have a distinct component composition as a different group from the modern roof tiles and their groups by specifications were further divided into subgroups. For example, small male roof tiles and roof-end tiles have all the samples in similar areas, while small female roof tiles and roof-end tiles have them relatively more distributed. To find out whether this is caused by the difference in contents or proportions of the ingredients, depending on the time of manufacture, further studies of comparison of the patterns and the shapes are required.

\subsubsection{Trace elements}

To identify relations and to estimate the provenance interpretation of trace elements in Joseon roof tiles, PCA was conducted with 12 compositions of trace elements (Table 3, Figure 10). In the case of modern roof tiles, a variety of materials are often mixed instead of using materials from a specific production area, so local characteristics are not 
72 | Journal of Conservation Science Vol.37, No.1, 2021

Table 3. Trace elements concentration of Joseon roof tiles

\begin{tabular}{|c|c|c|c|c|c|c|c|c|c|c|c|c|}
\hline \multirow{2}{*}{$\begin{array}{l}\text { Sample } \\
\text { number }\end{array}$} & \multicolumn{12}{|c|}{ Concentration (ppm) } \\
\hline & $\mathrm{La}$ & $\mathbf{T b}$ & Sm & $\mathbf{Y b}$ & Eu & $\mathbf{L u}$ & Sc & Co & $\mathrm{Cr}$ & $\mathbf{B a}$ & $\mathbf{R b}$ & Cs \\
\hline DAM1 & 10.20 & 0.15 & 1.51 & 0.36 & 0.24 & 0.06 & 7.31 & 30.0 & 92.1 & 691 & 116 & 5.85 \\
\hline DAM2 & 5.02 & 0.14 & 1.12 & 0.61 & 0.24 & 0.09 & 9.30 & 26.6 & 120.8 & 736 & 176 & 7.41 \\
\hline DAM3 & 4.90 & 0.11 & 1.04 & 0.40 & 0.17 & 0.06 & 6.36 & 28.2 & 122.2 & 717 & 126 & 6.69 \\
\hline DAM4 & 20.76 & 0.27 & 3.10 & 0.81 & 0.57 & 0.10 & 6.47 & 21.1 & 96.7 & 678 & 137 & 6.26 \\
\hline DAM5 & 7.30 & 0.18 & 1.46 & 0.50 & 0.20 & 0.10 & 8.10 & 27.8 & 125.7 & 735 & 164 & 7.48 \\
\hline DAM6 & 5.66 & 0.13 & 1.12 & 0.37 & 0.19 & 0.06 & 7.56 & 24.6 & 120.1 & 689 & 160 & 7.48 \\
\hline DAM7 & 5.77 & 0.09 & 0.88 & 0.22 & 0.11 & 0.05 & 5.23 & 23.5 & 100.4 & 781 & 127 & 6.28 \\
\hline DAM8 & 15.31 & 0.28 & 2.41 & 0.72 & 0.43 & 0.11 & 6.62 & 20.3 & 93.8 & 672 & 152 & 6.53 \\
\hline SAK1 & 21.57 & 0.76 & 5.05 & 2.16 & 1.15 & 0.33 & 15.15 & 21.05 & 112.9 & 765 & 155.7 & 7.03 \\
\hline SAK2 & 41.28 & 1.04 & 7.26 & 2.50 & 1.58 & 0.37 & 14.02 & 21.38 & 115.6 & 703 & 172.3 & 8.11 \\
\hline SAK3 & 1.54 & 0.08 & 0.54 & 0.36 & 0.24 & 0.06 & 6.62 & 25.27 & 139.1 & 399 & 120.8 & 5.64 \\
\hline SAK4 & 1.30 & 0.14 & 0.70 & 0.65 & 0.26 & 0.10 & 6.19 & 16.71 & 84.6 & 715 & 111.4 & 7.24 \\
\hline SAK5 & 0.66 & 0.06 & 0.30 & 0.28 & 0.20 & 0.04 & 9.23 & 21.67 & 139.5 & 725 & 110.8 & 7.92 \\
\hline SAK6 & 1.42 & 0.16 & 0.80 & 0.79 & 0.31 & 0.12 & 7.55 & 21.71 & 111.6 & 675 & 101.2 & 6.15 \\
\hline SAK7 & 2.33 & 0.16 & 0.89 & 0.60 & 0.30 & 0.09 & 7.00 & 23.26 & 112.1 & 693 & 111.3 & 6.91 \\
\hline SAK8 & 0.31 & 0.03 & 0.13 & 0.16 & 0.13 & 0.02 & 5.05 & 18.80 & 118.6 & 619 & 121.5 & 7.27 \\
\hline SAM1 & 8.92 & 0.41 & 2.87 & 1.28 & 0.71 & 0.19 & 8.09 & 25.07 & 146.2 & 628 & 132.5 & 6.47 \\
\hline SAM2 & 7.30 & 0.26 & 1.80 & 0.92 & 0.49 & 0.14 & 10.49 & 27.00 & 148.9 & 737 & 134.7 & 6.61 \\
\hline SAM3 & 2.63 & 0.14 & 0.85 & 0.56 & 0.34 & 0.08 & 10.65 & 29.50 & 147.7 & 572 & 145.2 & 6.92 \\
\hline SAM4 & 0.94 & 0.10 & 0.53 & 0.52 & 0.27 & 0.08 & 7.74 & 26.85 & 149.5 & 384 & 114.1 & 6.56 \\
\hline SAM5 & 2.13 & 0.23 & 1.20 & 0.98 & 0.38 & 0.15 & 7.04 & 29.01 & 147.3 & 748 & 102.3 & 6.04 \\
\hline SAM6 & 0.55 & 0.07 & 0.35 & 0.39 & 0.19 & 0.06 & 6.18 & 25.26 & 133.4 & 702 & 99.2 & 6.15 \\
\hline SAM7 & 0.49 & 0.06 & 0.30 & 0.42 & 0.20 & 0.06 & 5.43 & 22.13 & 123.8 & 715 & 63.2 & 4.85 \\
\hline SAM8 & 1.01 & 0.08 & 0.40 & 0.42 & 0.22 & 0.06 & 5.78 & 19.58 & 117.4 & 713 & 17.5 & 2.98 \\
\hline SSK1 & 1.80 & 0.15 & 0.78 & 0.67 & 0.27 & 0.10 & 5.56 & 18.62 & 107.8 & 695 & 106.0 & 5.70 \\
\hline SSK2 & 2.59 & 0.17 & 1.03 & 0.72 & 0.33 & 0.10 & 6.10 & 19.84 & 110.3 & 733 & 102.8 & 5.95 \\
\hline SSK3 & 13.64 & 0.61 & 4.14 & 1.96 & 0.90 & 0.30 & 11.71 & 19.85 & 112.0 & 744 & 125.1 & 6.64 \\
\hline SSK4 & 11.29 & 0.58 & 3.64 & 1.80 & 0.86 & 0.27 & 11.91 & 21.09 & 109.8 & 773 & 141.2 & 6.49 \\
\hline SSK5 & 5.66 & 0.34 & 1.99 & 1.12 & 0.53 & 0.17 & 12.64 & 22.15 & 116.1 & 731 & 145.4 & 6.89 \\
\hline SSK6 & 7.13 & 0.40 & 2.49 & 1.47 & 0.62 & 0.23 & 9.59 & 19.69 & 106.3 & 695 & 128.8 & 6.54 \\
\hline SSK7 & 0.78 & 0.09 & 0.45 & 0.51 & 0.20 & 0.08 & 6.37 & 23.69 & 133.7 & 715 & 124.8 & 6.07 \\
\hline SSK8 & 1.29 & 0.16 & 0.66 & 0.72 & 0.26 & 0.11 & 6.18 & 19.73 & 110.4 & 676 & 108.6 & 5.92 \\
\hline DAK1 & 3.50 & 0.32 & 1.83 & 1.28 & 0.46 & 0.19 & 7.08 & 18.54 & 101.6 & 625 & 93.0 & 6.38 \\
\hline DAK2 & 0.30 & 0.04 & 0.17 & 0.18 & 0.10 & 0.03 & 6.49 & 18.19 & 108.8 & 481 & 119.5 & 6.31 \\
\hline DAK3 & 2.12 & 0.21 & 1.17 & 0.95 & 0.39 & 0.15 & 8.55 & 24.75 & 130.0 & 699 & 120.9 & 5.98 \\
\hline DAK4 & 2.53 & 0.26 & 1.35 & 1.10 & 0.40 & 0.17 & 6.17 & 21.00 & 103.3 & 663 & 106.4 & 5.31 \\
\hline DAK5 & 0.48 & 0.07 & 0.34 & 0.37 & 0.16 & 0.06 & 3.38 & 17.19 & 95.1 & 709 & 103.6 & 5.07 \\
\hline
\end{tabular}


Scientific Comparison Study on the Joseon Dynasty Palace Roof Tiles and Modern Handmade Roof Tiles / Kyoung Suk Ahn et al. | 73

\begin{tabular}{|c|c|c|c|c|c|c|c|c|c|c|c|c|}
\hline \multirow{2}{*}{$\begin{array}{l}\text { Sample } \\
\text { number }\end{array}$} & \multicolumn{12}{|c|}{ Concentration (ppm) } \\
\hline & La & $\mathbf{T b}$ & Sm & $\mathbf{Y b}$ & Eu & Lu & Sc & Co & Cr & Ba & $\mathbf{R b}$ & Cs \\
\hline DAK6 & 1.08 & 0.12 & 0.59 & 0.54 & 0.22 & 0.08 & 7.26 & 25.47 & 101.8 & 704 & 114.4 & 5.59 \\
\hline DAK7 & 13.84 & 0.47 & 3.29 & 1.51 & 0.72 & 0.22 & 10.81 & 16.97 & 96.6 & 723 & 135.3 & 5.81 \\
\hline DAK8 & 0.29 & 0.03 & 0.17 & 0.19 & 0.13 & 0.03 & 4.83 & 24.69 & 136.1 & 771 & 117.1 & 6.62 \\
\hline DSM1 & 2.43 & 0.26 & 1.31 & 1.12 & 0.38 & 0.17 & 5.70 & 14.54 & 89.2 & 728 & 123.0 & 6.03 \\
\hline DSM2 & 0.35 & 0.04 & 0.18 & 0.23 & 0.12 & 0.03 & 3.34 & 13.34 & 78.9 & 719 & 85.6 & 5.49 \\
\hline DSM3 & 1.86 & 0.22 & 1.13 & 1.03 & 0.32 & 0.16 & 3.79 & 22.58 & 102.9 & 642 & 86.3 & 5.92 \\
\hline DSM4 & 0.15 & 0.02 & 0.08 & 0.11 & 0.08 & 0.01 & 1.83 & 18.12 & 85.8 & 724 & 92.8 & 5.71 \\
\hline DSM5 & 0.34 & 0.04 & 0.17 & 0.24 & 0.10 & 0.04 & 3.42 & 16.69 & 84.4 & 726 & 100.2 & 6.49 \\
\hline DSM6 & 0.29 & 0.03 & 0.12 & 0.16 & 0.08 & 0.02 & 1.94 & 16.72 & 86.5 & 638 & 86.2 & 5.70 \\
\hline SSM1 & 0.42 & 0.04 & 0.20 & 0.27 & 0.10 & 0.04 & 1.87 & 17.71 & 91.6 & 705 & 88.8 & 5.77 \\
\hline SSM2 & 1.41 & 0.14 & 0.79 & 0.61 & 0.24 & 0.09 & 2.89 & 19.46 & 98.8 & 706 & 102.4 & 6.33 \\
\hline TSK1 & 0.34 & 0.04 & 0.20 & 0.25 & 0.15 & 0.03 & 2.96 & 19.45 & 99.7 & 687 & 107.3 & 5.97 \\
\hline TSK2 & 1.97 & 0.14 & 0.77 & 0.55 & 0.26 & 0.08 & 6.77 & 18.50 & 90.0 & 636 & 140.7 & 6.58 \\
\hline TSK3 & 0.43 & 0.06 & 0.24 & 0.32 & 0.14 & 0.05 & 4.55 & 20.15 & 102.8 & 701 & 94.5 & 5.66 \\
\hline TSK4 & 0.06 & 0.00 & 0.02 & 0.04 & 0.06 & 0.00 & 3.30 & 16.82 & 97.0 & 593 & 68.0 & 4.74 \\
\hline TSK5 & 0.30 & 0.04 & 0.22 & 0.27 & 0.13 & 0.04 & 3.72 & 18.91 & 107.1 & 610 & 118.3 & 6.05 \\
\hline TSK6 & 0.29 & 0.06 & 0.22 & 0.35 & 0.14 & 0.06 & 5.57 & 15.86 & 110.9 & 650 & 104.0 & 7.01 \\
\hline TSK7 & 0.09 & 0.01 & 0.04 & 0.07 & 0.07 & 0.01 & 2.79 & 15.07 & 95.9 & 579 & 105.1 & 7.17 \\
\hline TSK8 & 0.53 & 0.06 & 0.29 & 0.29 & 0.12 & 0.04 & 5.68 & 14.48 & 91.5 & 599 & 92.4 & 5.21 \\
\hline
\end{tabular}

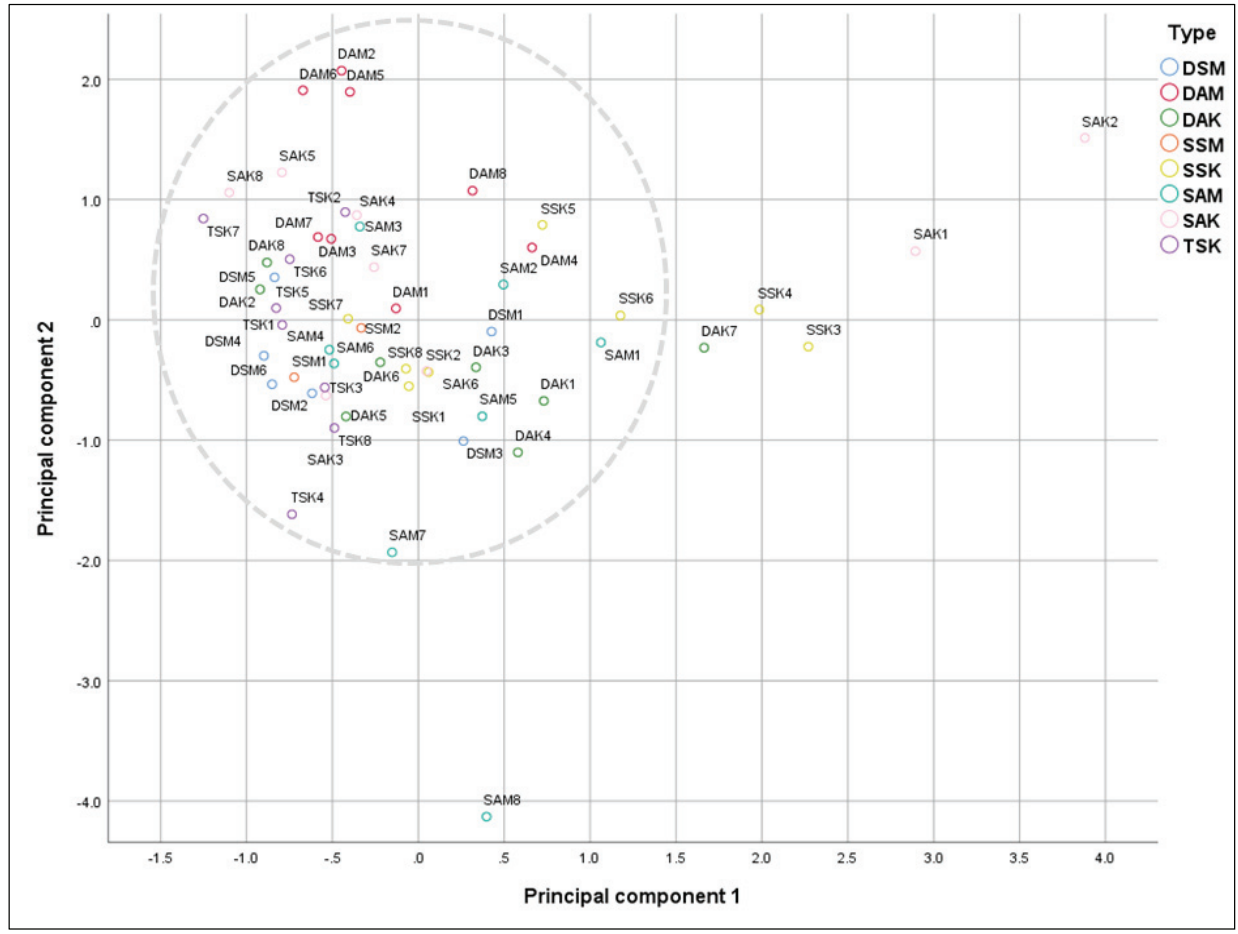

Figure 10. PCA results of trace elements of Joseon roof tiles; PCA, principal component analysis. 
revealed, so they were excluded from the analysis of trace components. Trace elements are indicative elements that reflect the depositional environment, and the trace elements contained in clay materials of potteries reflect mineralogical conditions of the ingredients used to manufacture potteries at the time. Not every element is used to assume the origin of the clay in a statistical method using trace elements. The contents of 12 elements, including rare earth elements and transition metals, with high stability and low mobility (La, $\mathrm{Tb}, \mathrm{Sm}, \mathrm{Yb}, \mathrm{Eu}, \mathrm{Lu}, \mathrm{Sc}, \mathrm{Co}, \mathrm{Cr}, \mathrm{Ba}, \mathrm{Rb}$, and $\mathrm{Cs}$ ), which are commonly used in studies to identify origins, were used for the statistical analysis. The analysis shows that most samples, except a few samples were illustrated in similar areas, and the distribution areas of groups with different specifications were overlapped, indicating that all the samples used clay materials from similar geological origins.

\subsection{Mineralogical analysis results}

Mineralogical analysis of the target samples identified minerals such as quartz, mica, alkali-feldspar, and plagioclase in all the samples and temperature indicator minerals such as hercynite and mullite in multiple samples (Figures 11 13).

For Joseon roof tiles, quartz, mica, and feldspar shared similar peak intensity, but some samples including SAM6, SSK8, DAK4, and TSK8 show sharp increases in the mica peak at $8^{\circ} 2 \theta$. It can be seen that mica was found and fired at a temperature of about $850^{\circ} \mathrm{C}$ or less. Also, in the sample in which mica was not confirmed, the hercynite produced when fired at about $1,000^{\circ} \mathrm{C}$ or more was confirmed, and the peak intensity was varied. Through this, it was confirmed that the Joseon roof tiles has a wide range from low-temperature firing to high-temperature firing. This can be attributed to the difference in factors such as shapes, firing conditions, and locations during firing, in addition to firing temperatures.

Modern roof tiles show more consistent results than Joseon roof tiles, with hercynite identified in all the samples and mullite in some samples. Also, mica does not show any diffraction peak, and feldspar also shows lower peak intensity than that of Joseon roof tiles, implying higher firing temperature than Joseon roof tiles, and it is estimated that they experienced a high temperature of about $1,000^{\circ} \mathrm{C}$ or higher. These results may be caused by the fact that technical development reduced gaps of firing conditions between

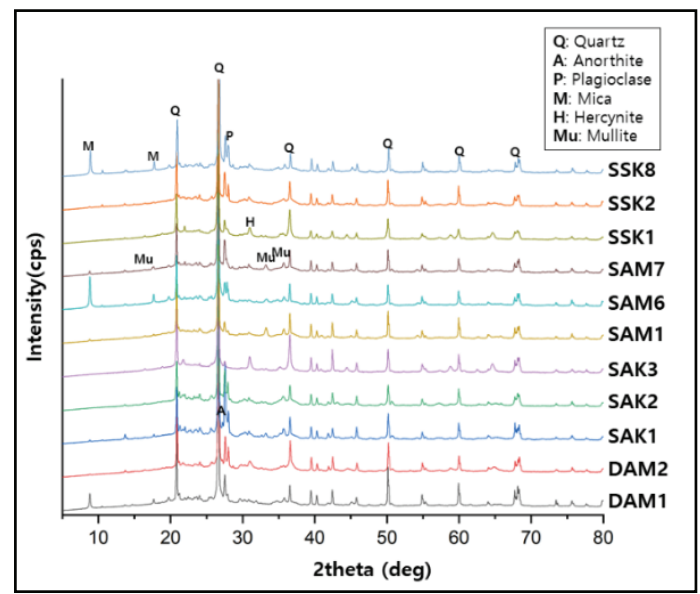

Figure 11. X-ray diffraction patterns of Joseon roof tiles from Changdeokgung material storage.

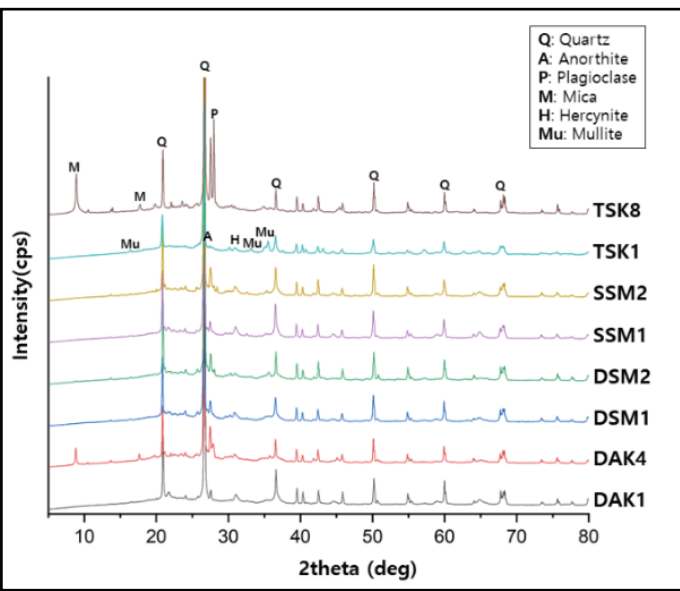

Figure 12. X-ray diffraction patterns of Joseon roof tiles from Seooreung Jaesil.

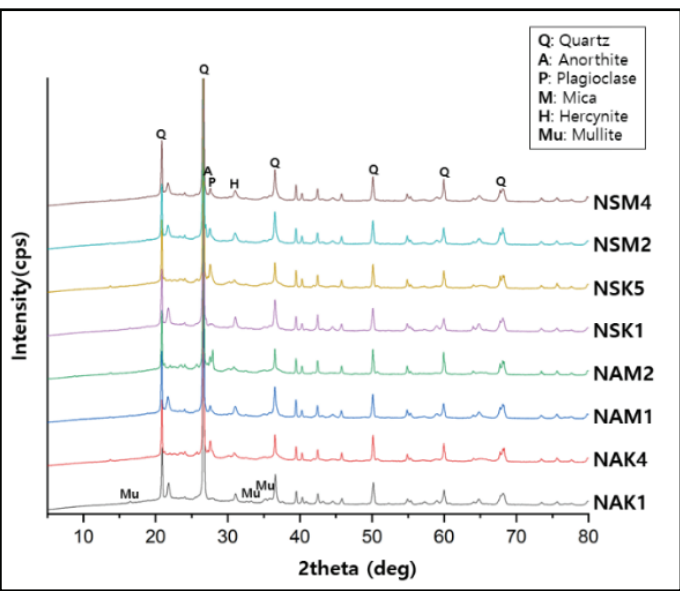

Figure 13. X-ray diffraction patterns of modern roof tiles. 
kilns, providing more consistent firing temperature and conditions.

\section{DISCUSSION AND CONCLUSION}

In this study, roof tiles were compared and analyzed for each production period and type of size based on scientific analysis data of the Joseon Dynasty roof tiles and modern handmade traditional roof tiles. First, for chromaticity, Joseon roof tiles have a wider range of chromatic values than modern roof tiles, which show concentrated distribution. This causes Joseon roof tiles to show more various colors in both surfaces and raw materials and difference in color between the surfaces and raw materials and modern roof tiles to show generally similar colors of surfaces and raw materials. It is also related to the X-ray diffraction analysis that reveals that Joseon roof tiles were fired at different temperatures, while modern roof tiles are fired at similar temperatures. Additionally, comparing the apparent porosity and water absorptions, Joseon roof tiles have higher values on average than modern roof tiles, and the cross sections of Joseon roof tiles show most clay minerals of the raw materials have not been vitrified but remaining in atypical particles. However, modern roof tiles have denser raw materials and more fine-grained mineral particles than Joseon roof tiles. The color and vitrification mentioned above were verified again in the composition mineral analysis. First, quartz, mica, alkali-feldspar, and plagioclase were found in all the samples, and temperature indicator minerals, such as hercynite and mullite, were found in multiple samples. The difference is that Joseon roof tiles have generally similar peak intensity of quartz, mica, and feldspar, but some samples show a high peak of mica, while modern roof tiles have more consistent diffraction patterns. Also, no peaks of low-temperature minerals, such as mica, were identified, implying that they are fired at a higher temperature than Joseon roof tiles.

This is thought to be because the kiln temperature is more easily adjustable for modern roof tiles than Joseon roof tiles, and colors show differences depending on the arrangement in the kiln and shapes of the roof tiles. However, it has to be considered that Joseon roof tiles may have differences in the time of manufacture, bunwaso (roof tile manufacturer), firing conditions, and craftsmanship of the masters involved in the manufacture, as Joseon roof tiles are from the supportive material storage of the Changdeokgung and Jaesil of the Seooreung Royal Tomb. Also, due to contamination by calcification or soils used in the manufacturing process and extended exposure to external environments, while being actually used in palaces, may have caused colors to change from the time of manufacture. Another consideration is that modern roof tiles were fired in one kiln on the same day under the same firing conditions. Also, cross sections of Joseon roof tiles show bigger mineral and atypical particles and different shapes of air bubbles, while modern roof tiles show higher density. The difference in density of cross sections may have been caused by the use of mixers and pugmills during the manufacture of modern roof tiles. In the Joseon Dynasty, mixers and pugmills are used to mix raw materials today, providing denser and more consistent cross sections than the raw materials that are refined manually. It seems to also affect the overall lower water absorption of modern roof tiles than Joseon roof tiles.

Analysis results of principal components and trace elements show that Joseon and modern roof tiles have generally similar principal components. Joseon roof tiles fall under a separate group from modern roof tiles, with differences in compositions of the ingredients. Their groups of each specification tend to be further divided into smaller groups. The PCA of trace element contents of Joseon roof tiles shows most samples in similar areas. This result implies that the roof tiles from Changdeokgung and Seooreung were supplied from the same region in the same timeframe because not only their sizes and shapes but also principal components and trace elements are similar. The contents of the principal components are also consistent, indicating that the mixing proportions of the clay materials were similar.

In conclusion, modern roof tiles are fired at a higher temperature than Joseon roof tiles and demonstrate higher density due to the use of machines such as pugmills. Also, the water absorption of Joseon roof tiles is higher than the $16 \%$ specified in the Standard Specifications of Properties. These results are expected to contribute to the establishment of a database on Joseon roof tiles and new standards for the roof tiles used in the field for the restoration of cultural properties through comparison and analysis of the roof tiles of Joseon palaces and commercial roof tiles and the roof tiles in temples. 


\section{ACKNOWLEDGMENTS}

This study was conducted with the support of the graduate research and development project of Korea National University of Cultural Heritage.

\section{REFERENCES}

Cultural Heritage Administration, 2012, Study on the activation plan of traditional rooftile and traditional tile. 98-156. (in Korean)

Cultural Heritage Administration, 2020, Standard Specification of Properties. 133-141. (in Korean)

Han, M.S., 2006, Scientific provenance study for Goryeo celadon excavated from seabed. Ph. D. thesis, ChungAng University, Seoul, 49-66. (in Korean with English abstract)
Kim, H.J., 2019, A study on The Roof-tile Production System and Technique of Bun-waso in the Late Chosun Dynasty. Master Dissertation, Korea National University of Cultural Heritage, Buyeo, 1-2. (in Korean with English abstract)

Kim, W.J. and Kim, S.S., 2005, Conservation and Reuse of Roof-tile. Review of Architecture and Building Science, 49(12), 66-73. (in Korean)

National Research Institute of Cultural Heritage, 2009, Report on the production of traditional rooftiles for the restoration of Sungnyemun. 78-146. (in Korean)

National Research Institute of Cultural Heritage, 2001, Dictionary of Korean Archaeology. National Research Institute of Cultural Heritage, Daejeon, 493-497. (in Korean)

Son, M.K., 2018, Mathematics that supports data analysis, Wikibooks, Paju, 109-157. (in Korean) 